
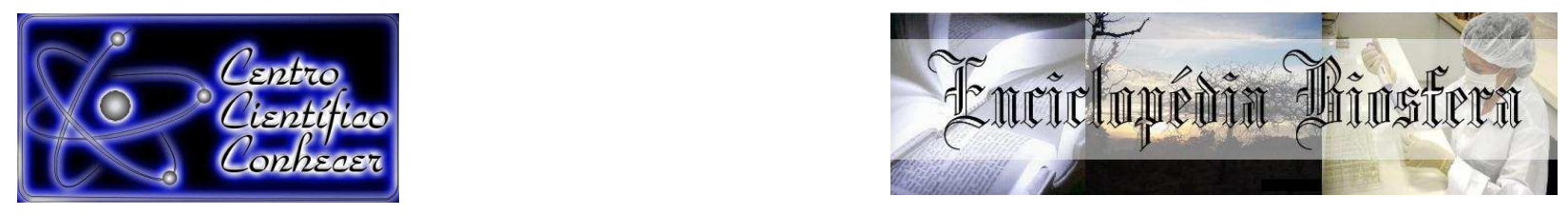

\title{
O DESENVOLVIMENTO E ANÁLISE DA INFRAESTRUTURA URBANA ESTUDO DE CASO: JARDIM NOVA ESPERANÇA GOIÂNIA- GO
}

\author{
Obede Rodrigues Alves ${ }^{1}$, Otniel Alencar Bandeira ${ }^{2}$, Elizeu Demambro ${ }^{3}$, Antônio \\ Pasqualetto $^{4}$ e Lucia Maria Moraes ${ }^{5}$.
}

${ }^{1}$ Doutoranda em Ciência da Engenharia Ambiental pela Universidade de São Paulo USP São Carlos.

${ }^{2}$ Mestrando em Desenvolvimento e Planejamento Territorial pela Pontifícia Universidade Católica de Goiás - PUC Goiás. Goiânia, Brasil. (otnielalencar@gmail.com)

${ }^{3}$ Mestrando em Desenvolvimento e Planejamento Territorial pela Pontifícia Universidade Católica de Goiás - PUC Goiás. Goiânia, Brasil

${ }^{4}$ Coordenador Doutor do Programa de Pós- Graduação em Desenvolvimento e Planejamento Territorial da Pontifícia Universidade Católica de Goiás - PUC Goiás ${ }^{5}$ Professora Doutora do Programa de Pós- Graduação em Desenvolvimento e Planejamento Territorial da Pontifícia Universidade Católica de Goiás - PUC Goiás.

\section{Recebido em: 08/04/2016 - Aprovado em: 30/05/2016 - Publicado em: 20/06/2016 DOI: 10.18677/Enciclopedia_Biosfera_2016_142}

\begin{abstract}
RESUMO
Goiânia, cidade planejada e construída na década de 1930, dentro dos critérios urbanísticos da Carta de Atenas, logo se viu crescendo além do plano diretor original. Tal crescimento foi induzido pela especulação imobiliária e pela população que chegava à cidade em busca de trabalho e acabava ficando sem condições de obter moradia digna e qualidade de vida. Dessa forma, as famílias que moravam de favor e/ou de aluguel buscavam resolver o problema construindo em espaços vazios, públicos ou privados, em vários lugares da cidade. O bairro Jardim Nova Esperança, foi construído por esse perfil de famílias no final da década de 1970 e foi resultado de um longo processo de lutas, contra a própria ditadura militar e forças armadas, que assumiu características distintas no que se refere à busca de solução para a questão da moradia. O objetivo do presente trabalho foi verificar as condições de infraestrutura urbana do Jardim Nova Esperança, a partir da percepção dos moradores e avaliar a aplicação dos parâmetros estabelecidos pelo Plano Diretor no bairro. Observa-se que, após 34 anos de existência, o bairro ainda carece de infraestrutura básica, como rede de esgoto, praças e equipamentos de saúde. Além disso, o bairro vem sendo alvo de especulação imobiliária, tornando-se verticalizado e atraindo diversos empreendimentos de grande porte.
\end{abstract}

PALAVRAS - CHAVE: Infraestrutura. Mutirão da moradia. Ocupação urbana. 


\title{
DEVELOPMENT AND ANALYSIS OF URBAN INFRASTRUCTURE CASE STUDY : NEW HOPE GARDEN GOIÂNIA- GO
}

\begin{abstract}
Goiania, a city planned and built in the 1930s within the urban criteria of the Charter of Athens soon found himself growing beyond the plan original director, this growth was induced by speculation and by the people who came to the city in search of work and ended up getting unable to obtain adequate housing and quality of life. Thus, families who lived to please and / or rental sought to solve their problem by building on empty spaces, public or private in various places in town. The Garden New Hope neighborhood was built for these families in the late 1970s and was the result of a long process of struggles against their military dictatorship and military, who took different characteristics with respect to the solution of search for issue of housing. The aim of this study was to assess the conditions of the urban infrastructure of New Hope Garden from the perception of residents and evaluate the application of the parameters established by the Master Plan in the neighborhood. 70 questionnaires were applied with questions related to leisure, health, education, public transportation, public safety and sanitation. It was observed that after thirty-four years of existence, the neighborhood still lacks basic infrastructure such as sewerage, parks and health equipment. In addition, the district has been real estate speculation target, becoming vertical and attracting several large enterprises.
\end{abstract}

KEYWORDS: Infrastructure. Housing of the task force. Urban occupation.

\section{INTRODUÇÃO}

As cidades são dinâmicas e diariamente sofrem modificações na organização espacial, isto porque as populações que a integram estão em constante interação com o espaço urbano, o meio ambiente, transformando-o, para adaptá-lo às suas necessidades. Grande parte dessa população não tem moradia digna e sequer participa da cidade urbanizada. Nos dizeres de MARICATO (2008) os gestores precisam estar atentos a esse movimento, a fim de garantir condições satisfatórias ao desenvolvimento e à redução da desigualdade social a todos.

Goiânia, cidade planejada e construída na década de 1930, dentro dos critérios urbanísticos da Carta de Atenas - morar, trabalhar, circular e recrear, logo viu seu crescimento ir além do plano diretor original, crescimento esse induzido pela especulação imobiliária e pela população que chegava à cidade em busca de trabalho e não tinha moradia para suas famílias (MOYSÉS, 2001).

VILLAÇA, (1998) realça que planejar o espaço urbano significa remeter-se ao futuro das cidades, buscando medidas de precaução contra problemas e dificuldades, ou, ainda, aproveitando melhor possíveis benefícios. É a partir do planejamento que surge um conjunto de ações, planos ou programas liderados pelo governo, com o objetivo de desenvolver o país, o estado ou o município, para alcançar determinados interesses.

De uma forma simples, pode-se dizer que a cidade de Goiânia perdeu sua forma de planejamento pretendido à época. Convém, pois, considerar que o processo de planejamento é um meio sistemático de determinar o estágio em que se encontra, onde se pretende chegar e qual o melhor caminho a ser tomado. $\mathrm{Na}$ opinião de SANTOS (2004), o planejamento não é algo estático e, sim, um processo 
contínuo que envolve coleta, organização e análise sistematizadas das informações para obtenção do melhor aproveitamento dos recursos disponíveis.

As famílias que moravam de favor e/ou de aluguel buscavam resolver o problema da casa própria construindo em espaços vazios, públicos ou privados, em vários lugares da cidade e, assim, as invasões de Goiânia fazem parte da história da cidade, planejada desde a sua construção. Fato que continua acontecendo ao longo do crescimento da cidade, sendo ocupações isoladas e planejadas pela articulação dos sem-teto, como o caso do Jardim Nova Esperança (MOYSÉS, 2001).

O bairro em estudo foi resultado de um longo processo de lutas que assumiu características distintas no que se refere à busca de solução para a questão da moradia. A ocupação e a criação do bairro estabeleceram um novo marco na luta pela terra urbana na cidade de Goiânia e, em especial, na região Noroeste e, de acordo com CHAVES (1985), foi, sem dúvida, a ocorrência local que conseguiu a maior cobertura da imprensa, ao longo do ano de 1979 e da década de 1980, e se transformou em um marco divisório na história das invasões na cidade planejada. $O$ planejamento de ocupações e a consolidação em bairros passa a ser uma constante nas urbes do Brasil.

O Jardim Nova Esperança completou, em 2015, 34 anos de existência, tornou-se um bairro como os demais da cidade entretanto, ainda carece de infraestrutura básica, como rede de esgoto, praças e equipamentos de saúde que possam atender, de modo satisfatório os seus habitantes. Dessa forma, não são poucos os bairros periféricos de Goiânia que já completaram mais de três ou quatro décadas de existência e permanecem com os mesmos problemas urbanos (MOYSÉS, 2001).

Dessa forma, o presente trabalho teve por objetivo verificar as condições de infraestrutura urbana do Jardim Nova Esperança - bairro periférico de Goiânia-GO a partir da percepção dos residentes e avaliar a aplicação dos parâmetros estabelecidos pelo Plano Diretor no bairro. Os aspectos avaliados foram: lazer; saúde pública; educação; transporte público, segurança pública e saneamento básico (abastecimento de água, rede coletora de esgoto e resíduos sólidos).

\section{MATERIAL E MÉTODOS}

\section{Caracterização da Área de Estudo}

A pesquisa foi realizada em Goiânia-GO, no período entre março de 2013 e dezembro de 2014, um estudo de caso sobre o Jardim Nova Esperança, um bairro consolidado e integrante da malha urbana do município de Goiânia. Na esfera municipal, o bairro faz parte da Região Mendanha; na esfera estadual integra a Região Noroeste do município. A situação do bairro foi classificada pelo IBGE (2010) como área urbanizada (Figura 1). 


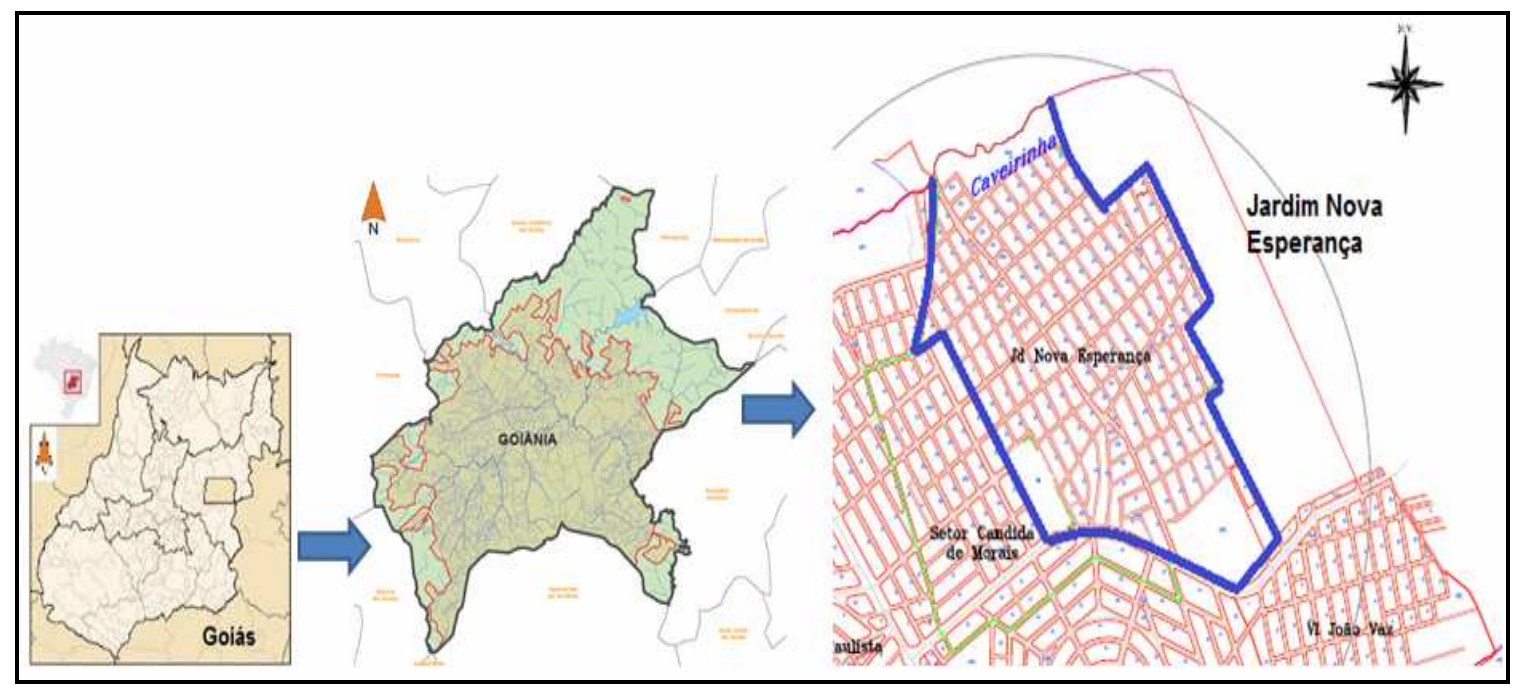

FIGURA 1 - Localização do Bairro Jardim Nova Esperança em Goiânia - GO Fonte: Organizado pelos autores in Plano Diretor de Goiânia, 2007.

Quanto à natureza desta pesquisa, objetivou gerar conhecimentos para aplicação prática, dirigidos à solução de problemas que envolvem verdades e interesses locais. Foi uma pesquisa essencialmente qualiquantitativa porque considerou que existe uma relação dinâmica e um vínculo indissociável entre o mundo objetivo e a subjetividade dos sujeitos, e que não podem ser traduzidas em números (SANTOS, 1999).

\section{Método}

A pesquisa foi dividida em três etapas: 1) pesquisa teórica; 2) elaboração, teste e aplicação do questionário a residentes do Jardim Nova Esperança; 3) tabulação e interpretação dos dados.

A pesquisa teórica foi realizada em artigos, documentos e livros que contam a história do bairro, desde a sua ocupação, levantamento e coleta de dados secundários no Plano Diretor de Goiânia, do Anuário Estatístico de Goiânia, disponibilizados pela Secretaria de Planejamento Urbano Sustentável de GoiâniaSEMDUS, dados estatísticos do Censo 2010 sobre o Jardim Nova Esperança disponibilizado pelo Instituto Brasileiro de Geografia e Estatística - IBGE. O estudo bibliográfico foi realizado a partir de bases científicas, como Scielo, Science Direct, Scopus, banco de dissertações e teses da Universidade de São Paulo, Universidade Federal de Goiás e Universidade Federal do Rio de Janeiro.

A segunda etapa correspondeu à elaboração do questionário para avaliação de itens previamente selecionados sobre infraestrutura urbana, a saber: oferta de lazer (praças, esporte, equipamentos culturais); saúde pública (postos de saúde); educação; transporte público, segurança pública e saneamento básico (abastecimento de água, rede coletora de esgoto e resíduos sólidos). Os questionários foram aplicados a 70 residentes do Jardim Nova Esperança que avaliaram os itens por meio de atribuição de conceitos "ótimo", "bom", "regular" e "ruim". A terceira e última etapa correspondeu à tabulação dos dados obtidos pelo questionário, interpretação e elaboração de redação final da pesquisa. 


\section{RESULTADOS E DISCUSSÕES}

O plano diretor de Goiânia estabelece parâmetros urbanísticos quase utópicos, pela dificuldade de serem alcançados e apresenta medidas de melhorias muito genéricas e pouco aplicáveis no ambiente urbano, como os resultados de pesquisa do Jardim Nova Esperança.

O bairro possui 5.091 domicílios particulares permanentes ${ }^{1}$, dos quais 4.794 são do tipo casa. No bairro há predominância de residências horizontais e comércios de pequeno a médio porte, para atender à demanda da população local e região (Figura 2). Importante realçar que a questão fundiária das unidades habitacionais não foi resolvida até a presente data, apenas algumas unidades receberam a escritura do imóvel, conforme afirmativa de VEIGA (2002) a questão fundiária está relacionada à dificuldade de acesso à terra urbanizada, bem localizada, regularizada e com infraestrutura, para os segmentos de baixa renda, tendo em vista a crônica concentração da propriedade e a normativa urbanística excludente reproduzida nos Planos Diretores, Leis de Uso e Ocupação do Solo, Leis de Parcelamento e Códigos de Obras e Edificações (VILLAÇA 1999). A maioria destas edificações foram construídas durante a ocupação, passando por reformas, ampliações e mudanças de uso ao longo da existência do bairro, cuidadosamente construída pelos posseiros na década de 1980.

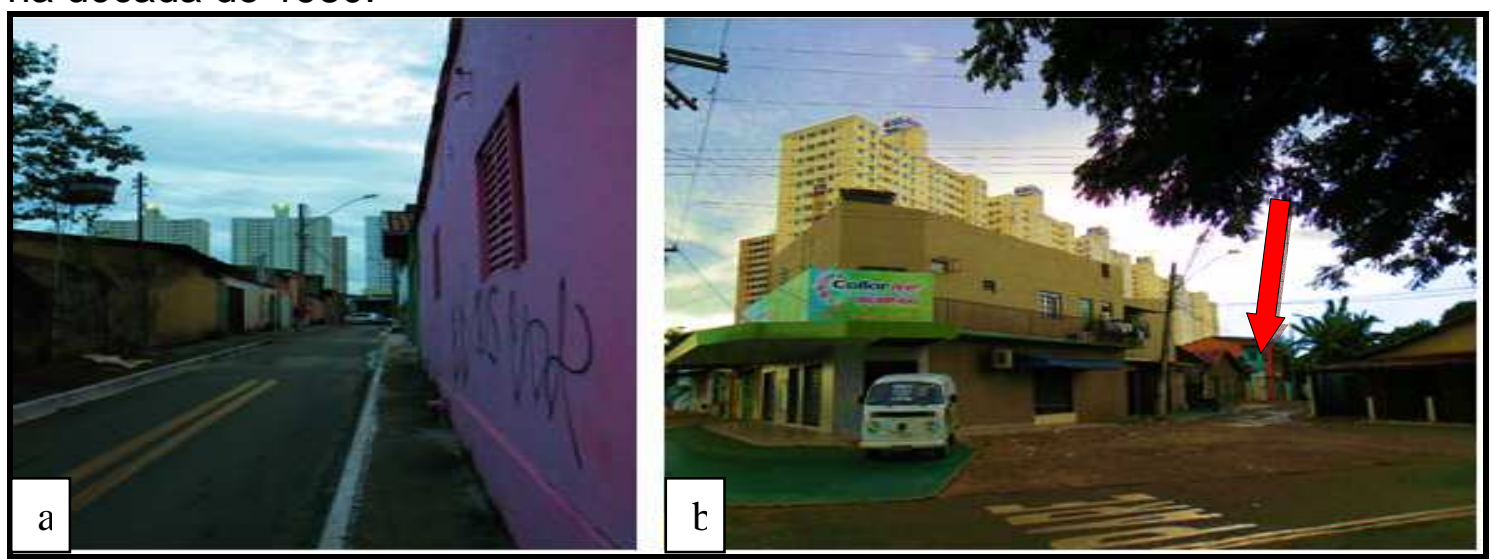

FIGURA 2 - Imagens dos tipos de residências predominantes no bairro (a) e pequenos comércios (b), Goiânia, GO

Fonte: Os autores, 2013.

Na Figura 2a é possível observar o tipo de residência predominante no local; são residências horizontais, casas muito simples, calçadas e ruas estreitas; é o retrato histórico do bairro onde o loteamento, com traçado urbano simples, foi desenhado e implantado pelos moradores. Na Figura $2 b$ observa-se a presença de alguns pequenos comércios, calçadas de tamanho irregular, largura da caixa viária sem padronização (nota-se que a seta aponta para uma rua que dá acesso à calçada). As figuras mostram os edifícios verticais construídos no bairro, que busca uma nova ordem urbana.

A população do bairro foi calculada pelo IBGE (2010) em 15.231 pessoas. Do total, 6.101 são pessoas de cor ou raça branca, 864 de cor ou raça preta, 7.983 pardos, 270 amarelos e 13 indígenas. No que se refere à renda percebe-se que em

\footnotetext{
${ }^{1}$ Quanto à condição de ocupação, os domicílios são classificados pelo IBGE como: Próprios e quitados; Próprios e em aquisição; Alugados; Casa: cedidos por empregador; Cedidos de outra forma e em outra condição
} 
quase todos os domicílios, exatamente 4.362, predomina rendimento de, no máximo dois salários mínimos (IBGE, 2010a). Segundo informações obtidas na Associação de Moradores do bairro 30\% dessa população são pioneiros, ou seja são posseiros e ou decentes das famílias que ocuparam o terreno no ano de 1979.

\section{a) Lazer}

Conforme o Plano Diretor de Goiânia (PDG) os parâmetros para praças e parques de vizinhança são de uma unidade para cada 10.000 hab. em um raio de influência máximo de $600 \mathrm{~m}^{2}$. Na relação de parques e bosques, existentes por bairro em Goiânia, obtida a partir de informações da Agência Municipal de Meio Ambiente - AMMA, não existem parques ou bosques no setor Jardim Nova Esperança e região, ou dentro do raio de influência estabelecido pelo PD. Isso pode ter influenciado de forma negativa a avaliação do primeiro item pesquisado como mostra a Figura 3:

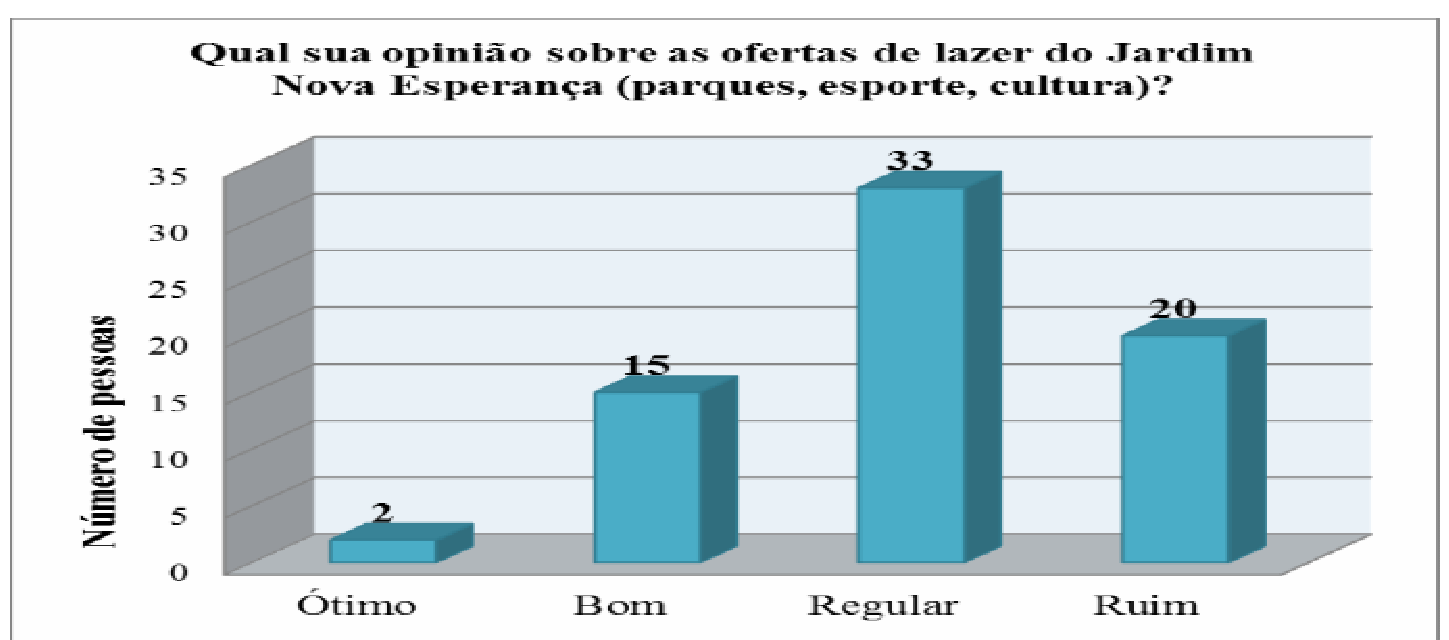

FIGURA 3 - Comparação de notas atribuídas pelos moradores ao item lazer no bairro Jardim Nova Esperança em Goiânia - Goiás.

Fonte: Elaborado pelos autores.

Os residentes avaliaram o item lazer, levando em consideração a existência de parques e/ou bosques, quadras de esportes e equipamentos culturais. Observase que, na percepção de 33 residentes, o aspecto lazer foi avaliado como regular, 20 atribuíram conceito ruim, enquanto 15 pessoas avaliaram o lazer existente no bairro como bom.

Algumas opções de lazer que a população do Jardim Nova Esperança possui são os shoppings centers localizados próximos ao bairro, sendo: o Portal Shopping e o Shopping Passeio das Águas, empreendimentos contemporâneos. No entanto, o custo para se divertir nesses locais é oneroso à população do bairro, que possui baixa renda.

O lazer é um aspecto importante da função social da cidade e da garantia do direito a cidades sustentáveis. É durante o lazer que os moradores compartilham espaços de recreação e mantêm o contato social, fortalecendo os relacionamentos humanos, seja na esfera familiar ou social. CHAMIÉ (2012) destaca que a cidade cumpre a função social no momento em que oferece aos habitantes as condições necessárias para a sobrevivência. 
Com relação aos equipamentos culturais, os museus e centros culturais de Goiânia estão localizados no Setor Central, Setor Oeste, Setor Sul, Setor Bueno, Parque Atheneu, Leste Universitário e Setor Campinas (GOIÂNIA, 2011b). Não há museus e/ou centros culturais no Jardim Nova Esperança, tampouco em bairros próximos que estejam dentro do raio de influência de $2.500 \mathrm{~m}$ e $5.000 \mathrm{~m}$ do bairro, parâmetro estabelecido pelo PDG. Sobre o acesso ao esporte não existem quadras de esportes em áreas públicas no Jardim Nova Esperança ou em bairros que estejam dentro do raio de influência de 2.000 m estabelecido pelo PDG.

\section{b) Saúde}

A saúde é um dos aspectos mais importantes para a sociedade moderna. $O$ acesso aos equipamentos de saúde e atendimento humanizado é direito de todo cidadão brasileiro. Um importante programa criado pelo governo foi o Programa Saúde da Família que objetiva humanizar as práticas de saúde, criando vínculo entre os profissionais de saúde e a população. Neste programa os agentes de saúde realizam visitas domiciliares e orientam as famílias sobre prevenção e tratamento de doenças, a fim de evitar o deslocamento desnecessário às Unidades de Saúde e concomitantemente combater doenças locais, antes que se tornem epidemias.

A Figura 4 refere-se aos conceitos atribuídos pelos residentes ao aspecto saúde que incluiu os postos de saúde e Centro de Assistência Integral à Saúde (CAIS).

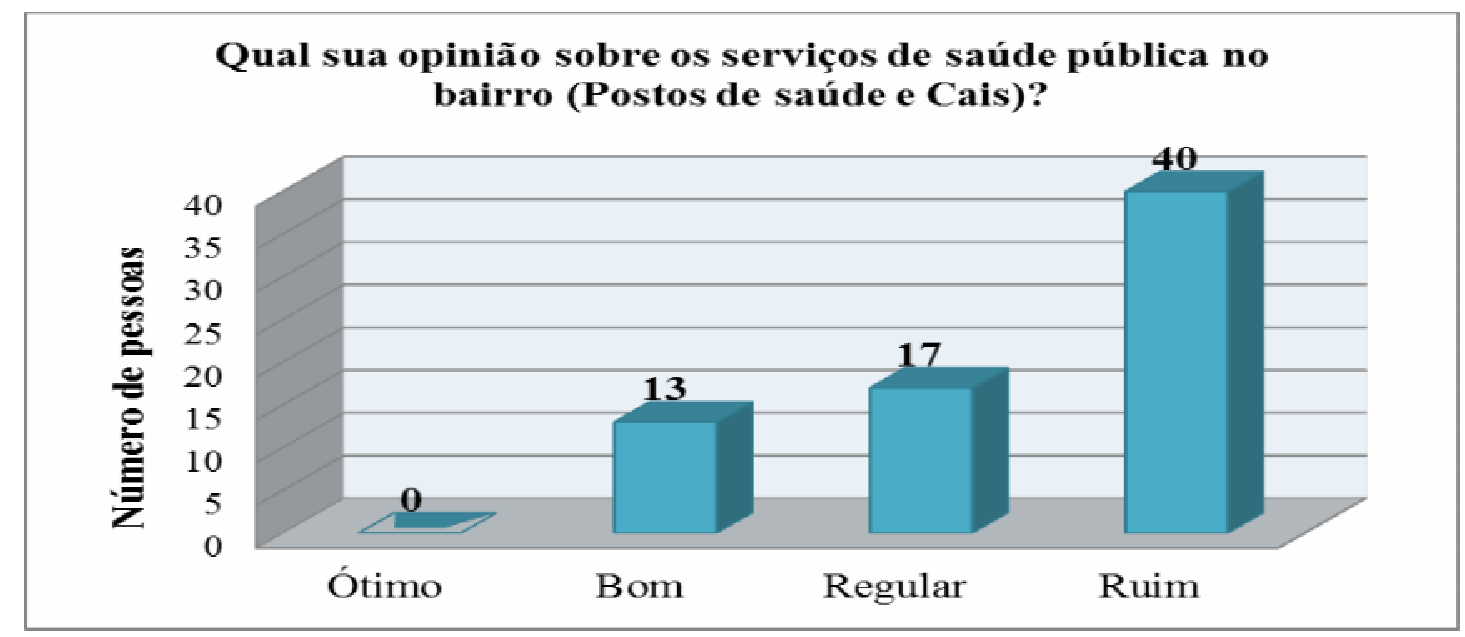

FIGURA 4 - Comparação de notas atribuídas pelos moradores ao item saúde no bairro Jardim Nova Esperança em Goiânia - Goiás.

Fonte: Elaborado pelos autores.

Das 70 pessoas que responderam ao questionário, 40 e 13 atribuíram conceito ruim e bom, respectivamente, para os serviços de saúde pública. $O$ parâmetro estabelecido pelo Plano Diretor para equipamentos de saúde é um posto de saúde para cada 3.000 mil habitantes, em raio de influência máximo de 1.000 metros e para os CAIS o recomendado é uma unidade para cada 30.000 habitantes, em raio de influência máximo de 5.000 metros. Entretanto, não existe nenhum posto de saúde, dentro dos parâmetros estabelecidos pelo PDG, que atenda à população do Jardim Nova Esperança, sendo que os residentes deste bairro contam apenas com o atendimento do CAIS, no setor Cândida de Moraes. Os equipamentos de saúde encontram-se deficientes no setor e, para atender ao estabelecido pelo PDG, 
deveria existir, pelo menos, cinco postos de saúde no bairro, no entanto, essa necessidade é suprida pelo CAIS pelo porte e resolutivadade do mesmo.

\section{c) Educação}

A Figura 5 refere-se à avaliação do aspecto educação:

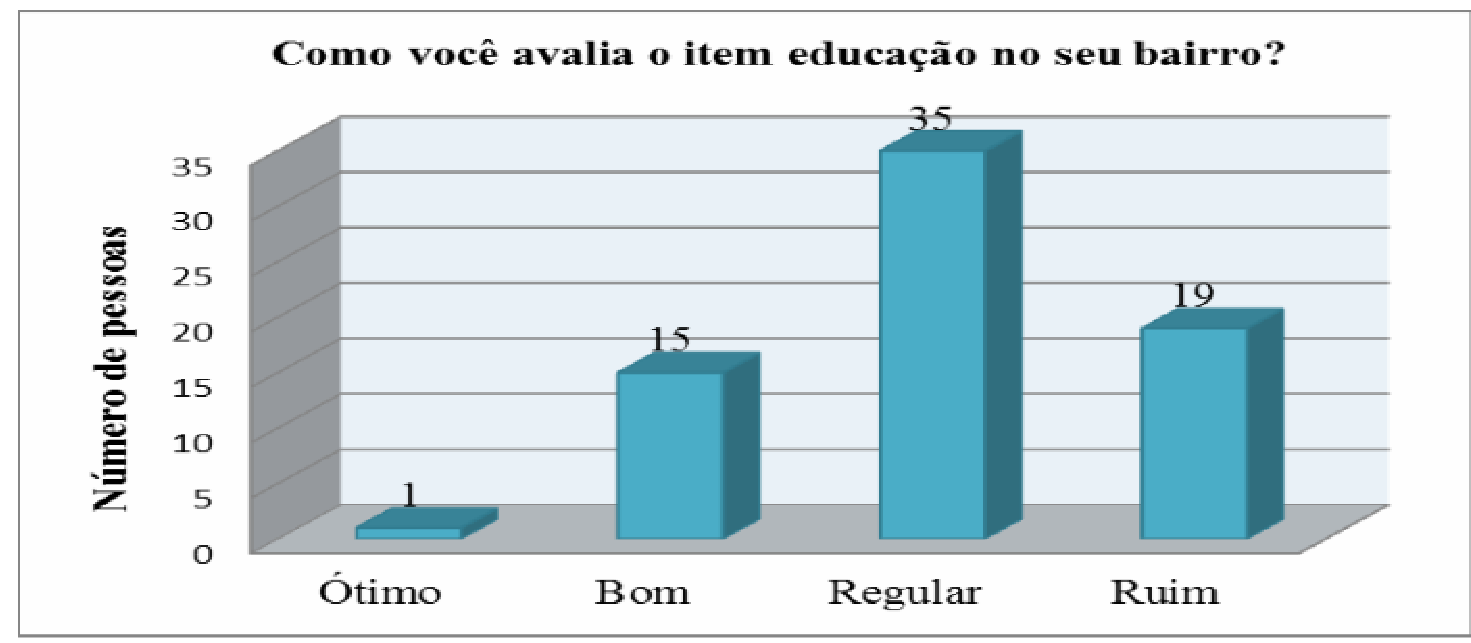

FIGURA 5 - Comparação de notas atribuídas pelos moradores ao item educação no bairro Jardim Nova Esperança em Goiânia - Goiás.

Fonte: Elaborado pelos autores.

Dentro do item educação, nota-se que os residentes ficaram bem divididos, sendo que uma pessoa avaliou como ótimo, entretanto, para bom e ruim ficou quase a mesma quantidade, ou seja, bom: 15 pessoas e ruim: 19. Ao mesmo tempo, 35 pessoas consideraram a educação regular.

O Plano Diretor estabelece que os equipamentos de educação são divididos em três categorias: Centro de Educação Infantil; Centro de Ensino Fundamental e Centro de Ensino Médio. O Centro de Educação Infantil se refere à creche, maternal e jardim da infância, devendo possuir, no máximo, 300 alunos por equipamento (GOIÂNIA, 2007).

Os estabelecimentos de Educação Infantil que atendem à população do Jardim Nova Esperança estão listados no Quadro 1.

QUADRO 1 - Centros de Educação Infantil da Rede Municipal de Educação de Goiânia, dentro do raio de influência máximo de $300 \mathrm{~m}$, a partir do empreendimento residencial.

\begin{tabular}{|l|l|c|c|}
\hline NOME & BAIRRO & SALAS (№) & MATRÍCULAS (No) \\
\hline $\begin{array}{l}\text { CMEI Herdeiros do Futuro } \\
\text { (Antigo Capuava II) }\end{array}$ & Bairro Capuava & 3 & 53 \\
\hline CMEl Jardim Nova Esperança & Jardim Nova Esperança & 8 & 155 \\
\hline CMEI Setor Santos Dumont & Setor Santos Dumont & 4 & 87 \\
\hline CMEI Vivendo e Aprendendo & Bairro Capuava & 3 & 51 \\
\hline
\end{tabular}

Fonte: Organizado pelos autores in Secretaria Municipal de Educação - SME/

Departamento de Administração Educacional - DAE. (GOIÂNIA, 2011a). 
A lei do plano aponta que cada equipamento poderá ter até 300 alunos, no entanto, não estabelece o número máximo de alunos por sala, fato que dificultou a análise do impacto sobre esse equipamento. Levando em consideração apenas o parâmetro do PDG, observa-se, a partir do Quadro 1, a existência de quantidade significativa de vagas a serem preenchidas nos referidos centros de educação infantil (854 vagas, no total). Dessa forma, os equipamentos existentes para educação infantil são suficientes para atender às futuras demandas populacionais no bairro e região.

\section{d) Transporte público}

A questão do transporte público é um tema muito discutido em Goiânia, sendo um dos maiores desafios ao planejamento urbano da capital. A frota de ônibus existente não tem sido suficiente para atender à demanda e os terminais não oferecem estrutura física adequada aos usuários (Figura 6).

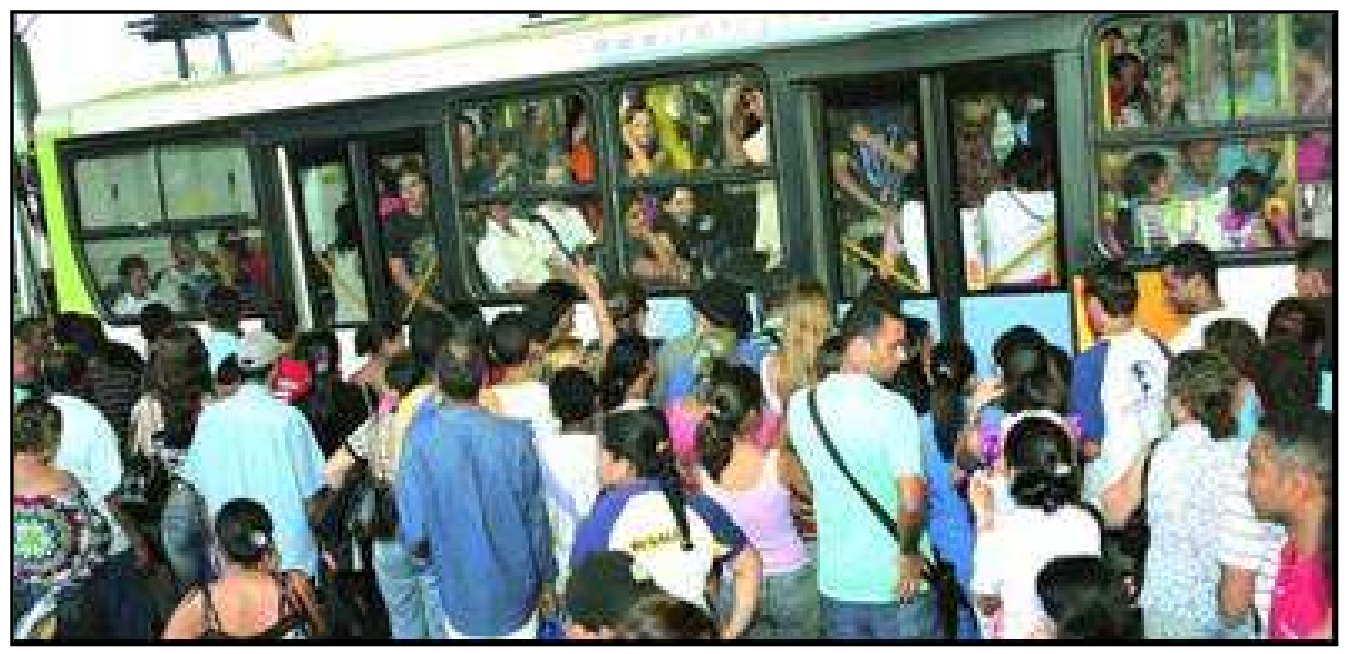

FIGURA 6 - Situação do transporte público no Terminal Padre Pelágio que atende aos residentes do Jardim Nova Esperança e região Mendanha.

Goiânia - Go

Fonte: Jornal Opção, $2013^{2}$.

Em 2012, a Ordem dos Advogados do Brasil (OAB) iniciou vistoria em todos os terminais de ônibus de Goiânia. O relatório da vistoria apontou que há violação dos princípios de dignidade humana previstos na Constituição Federal, na Política Nacional de Mobilidade Urbana (Lei 12.587/2012) e no Plano Diretor de Goiânia (Lei 171/2007). O relatório da OAB concluiu que o "Terminal Padre Pelágio não oferece o mínimo de dignidade, ofendendo frontalmente direitos da pessoa humana, devendo ser objeto de interdição urgente até que se ofereça um serviço com um mínimo de dignidade aos usuários do transporte público". No entanto, as irregularidades apontadas continuam e ainda nenhuma providência foi tomada, tanto da parte da Prefeitura Municipal quanto das prestadoras de serviços, a Rede Metropolitana do Transporte Coletivo (RMTC) e Metrobus.

A Figura 7 refere-se à avaliação do aspecto transporte público:

\footnotetext{
${ }^{2}$ (http://www.jornalopcao.com.br/posts/reportagens/oab-diz-que-transporte-publico-fere-a-dignidadedas-pessoas).
} 


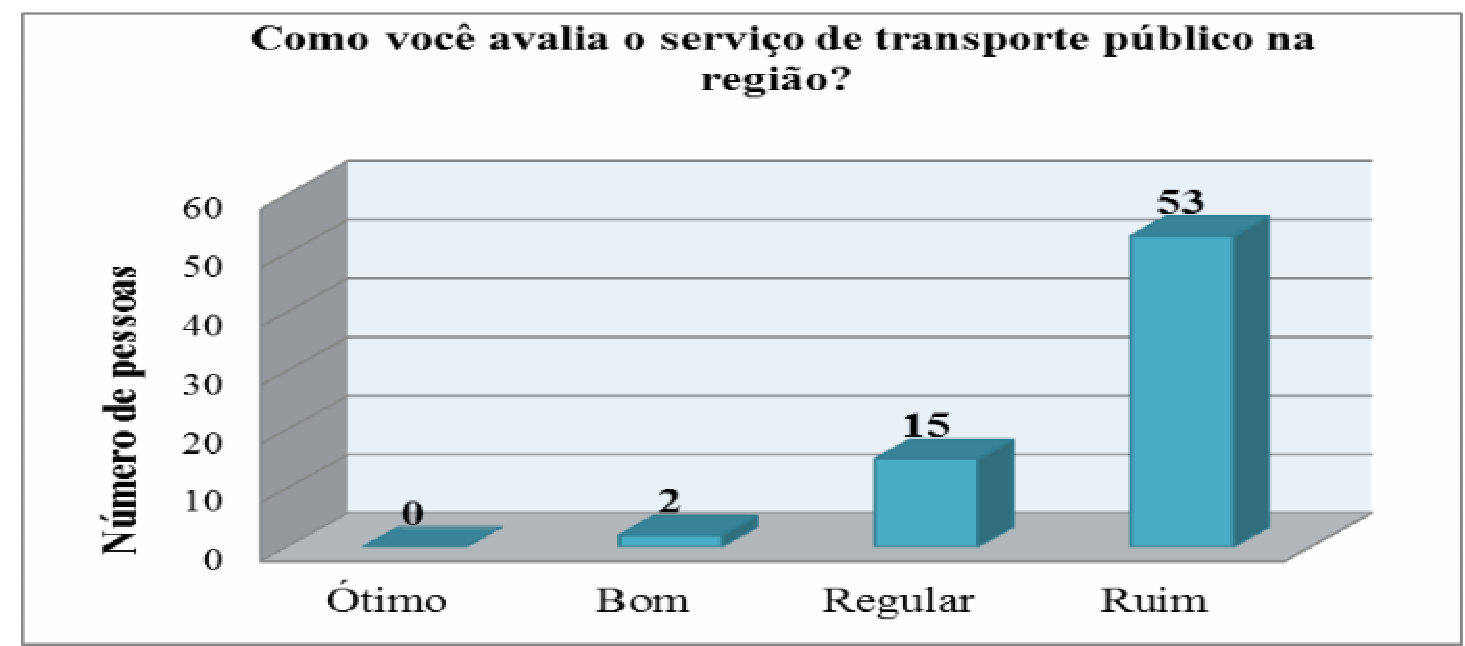

FIGURA 7 - Comparação de notas atribuídas pelos moradores ao item de transporte público no bairro Jardim Nova Esperança em Goiânia - Goiás.

Fonte: Elaborado pelos autores.

Após o relatório da $O A B$ sobre o transporte público, em Goiânia, não é espantoso o fato de 53 pessoas terem avaliado este item como ruim na região. Se as condições dos terminais de ônibus ferem a dignidade humana, trazendo a discussão para os pontos de ônibus, a situação também não é diferente. O PDG aponta que devem existir pontos de ônibus em um raio de influência de $500 \mathrm{~m}$, porém este parâmetro é muito geral, não sendo suficiente para indicar se atende ou não à população. A RMTC aponta que existem 22 pontos de embarque e desembarque de passageiros no Jardim Nova Esperança, sendo as linhas que atendem ao bairro descritas no Quadro 2.

QUADRO 2 - Linhas de ônibus presentes no Jardim Nova Esperança. Goiânia- GO

\begin{tabular}{|c|l|}
\hline NÚMERO DA LINHA & \multicolumn{1}{|c|}{ DESTINO DO ÔNIBUS } \\
\hline 36 & $\begin{array}{l}\text { Terminal Recanto do Bosque } \\
\text { Terminal Padre Pelágio }\end{array}$ \\
\hline 134 & $\begin{array}{l}\text { Terminal Padre Pelágio } \\
\text { Jardim Curitiba }\end{array}$ \\
\hline 136 & $\begin{array}{l}\text { Terminal Padre Pelágio } \\
\text { Novo Planalto }\end{array}$ \\
\hline 305 & $\begin{array}{l}\text { Campinas } \\
\text { Terminal Recanto do Bosque }\end{array}$ \\
\hline 717 & $\begin{array}{l}\text { Terminal Padre Pelágio } \\
\text { Jardim Vitória }\end{array}$ \\
\hline 152 & $\begin{array}{l}\text { Terminal Padre Pelágio } \\
\text { Albi Boa Ventura }\end{array}$ \\
\hline
\end{tabular}

Fonte: Organizado pelos autores in Website da Rede Metropolitana de Transportes Coletivos - RMTC (GOIÂNIA, 2015).

O Plano Diretor de Goiânia não estabelece o parâmetro que será mostrado adiante, no entanto, é interessante calcular se a quantidade de pontos de ônibus existentes seria suficiente para atender a toda a população do bairro, caso ela usasse somente o transporte público. Dividindo a população total do bairro (15.231 ENCICLOPÉDIA BIOSFERA, Centro Científico Conhecer - Goiânia, v.13 n.23; p.1602 
habitantes) pelo número de pontos de ônibus existentes (22), o resultado seria aproximadamente um ponto de ônibus para cada 692 pessoas. Esses valores sugerem que a questão do transporte público no setor necessita ser reavaliada pelos técnicos da RMTC e órgãos de planejamento da cidade.

Os pontos de embarque e desembarque de passageiros precisam ser reformados e possuir informações sobre trajeto e horário de ônibus, não somente no Jardim Nova Esperança como também nos demais setores da cidade, especialmente os periféricos. A frota de ônibus necessita ser ampliada, os terminais precisam passar por reforma, a fim de atender às regras estabelecidas pelas normas técnicas de segurança e acessibilidade.

\section{e) Segurança pública}

A região mendanha, onde se localiza o Jardim Nova Esperança, é considerada uma das regiões mais violentas do município. Os índices de violência urbana também estão relacionados com a desigualdade social e a concentração de renda na cidade. CARVALHO FILHO (2011) considera que todos os rankings de violência por bairros mostram que os números são maiores em bairros periféricos.

A Figura 8 expõe os resultados da avaliação do item segurança pública:

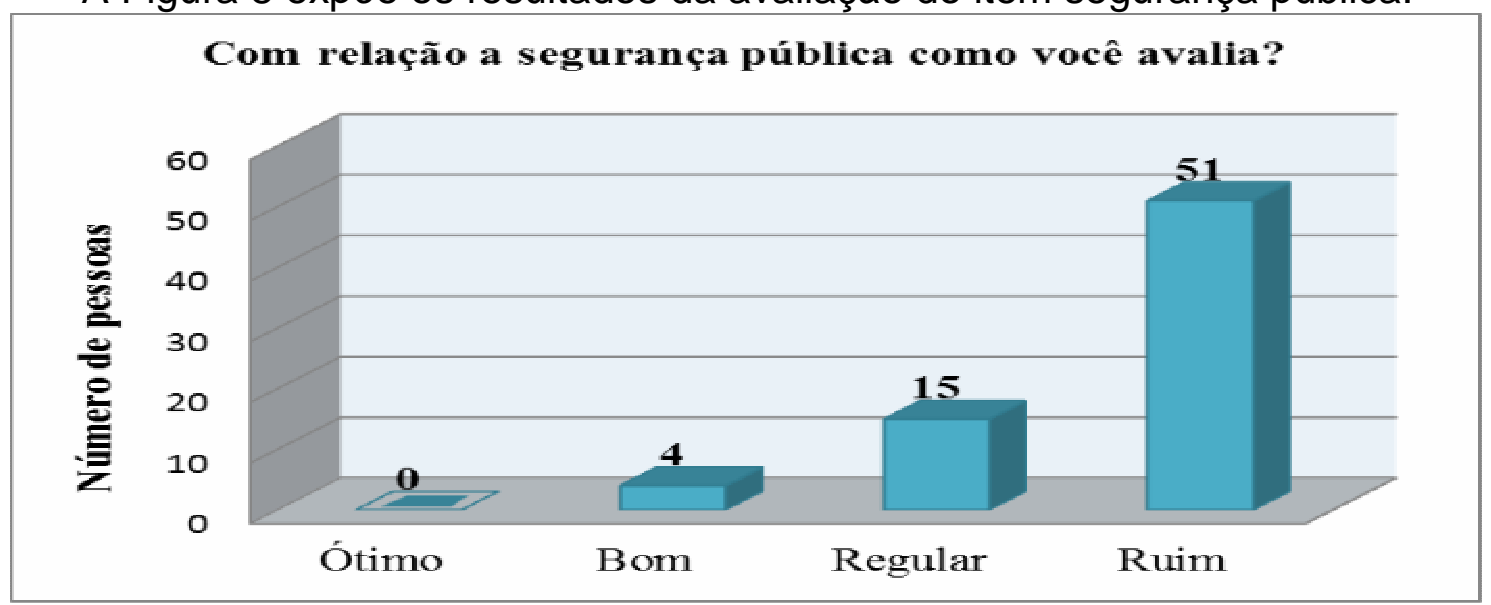

FIGURA 8 - Comparação de notas atribuídas pelos moradores ao item de segurança pública no bairro Jardim Nova Esperança em Goiânia - Goiás.

Fonte: Elaborado pelos autores.

Observa-se que 51 pessoas atribuíram conceito ruim ao item segurança pública, 15 e quatro atribuíram conceito regular e bom, respectivamente. O PDG estabelece que deve existir uma unidade de posto policial para cada 20.000 habitantes, em raio de influência máximo de 2.000 m (GOIÂNIA, 2007).

O 16을 Distrito Policial localizado na Avenida Central, no Jardim Nova Esperança, deveria atender, de acordo com o PDG, apenas a 20.000 hab. em um raio de influência de $2.000 \mathrm{~m}$. Apenas o bairro onde o distrito se localiza possuía em 2010 o equivalente a 15.209 habitantes; somando com a população de alguns bairros que estão dentro do raio de 2.000 m, como, por exemplo, o Setor Cândida de Moraes (2.398 hab.), o Bairro Santos Dumont (12.198 hab.) a Vila Regina (2.138 hab.) e o Parque Industrial Paulista (1.387 hab.), o total de habitantes atendidos por este posto policial ultrapassa 33.330 habitantes (IBGE, 2010).

Dessa forma, pode-se dizer que os equipamentos de segurança da região já encontram-se sobrecarregados e ficarão mais ainda com o incremento populacional advindo de futuros empreendimentos residenciais que atrairão novos moradores. 
Um agravante à sobrecarga do equipamento de segurança é o fato de 0 Jardim Nova Esperança possuir altos índices de violência (GOIÁS, 2011). Uma alternativa para a questão da segurança seria a criação de mais uma unidade policial no bairro, ou dentro da área de influência.

\section{f) Saneamento básico}

Concernente ao tipo de abastecimento de água no Jardim Nova Esperança, 4.737 domicílios do tipo casa (98\%) do total de 4.797 são contemplados com a rede geral de abastecimento (IBGE, 2010b). O mesmo não acontece com os efluentes domésticos; no bairro não existe rede coletora de esgoto e o tipo de esgotamento sanitário predominante no local é via fossa rudimentar.

A Tabela 1 apresenta a característica do tipo de esgotamento sanitário do banheiro ou sanitário dos domicílios do Jardim Nova Esperança.

TABELA 1 - Tipo de esgotamento sanitário nos domicílios tipo casa no Jardim Nova Esperança, 2010. Goiânia - GO

\begin{tabular}{lc}
\hline Tipo de esgotamento sanitário & Quantidade (nº) \\
\hline Esgotamento sanitário via rede geral de esgoto ou & 137 \\
pluvial & 537 \\
Esgotamento sanitário via fossa séptica & 4116 \\
Esgotamento sanitário via fossa rudimentar & 4 \\
Esgotamento sanitário via vala, rio, lago e/ou outro & $\mathbf{4 7 9 4}$ \\
\hline escoadouro & \\
\hline Total &
\end{tabular}

Fonte: Organizado pelos autores in IBGE (2010)

Observa-se pela Tabela 1 que os residentes do Jardim Nova Esperança ainda não são atendidos em seus domicílios com rede geral de esgoto e, mesmo após 34 anos de existência, o tipo de esgotamento sanitário predominante no bairro é via fossa rudimentar $(86 \%)$. Nota-se com isso o descaso das autoridades municipais com relação à melhoria de infraestrutura básica no bairro. básico:

A Figura 9 mostra as notas atribuídas pelos moradores ao item saneamento

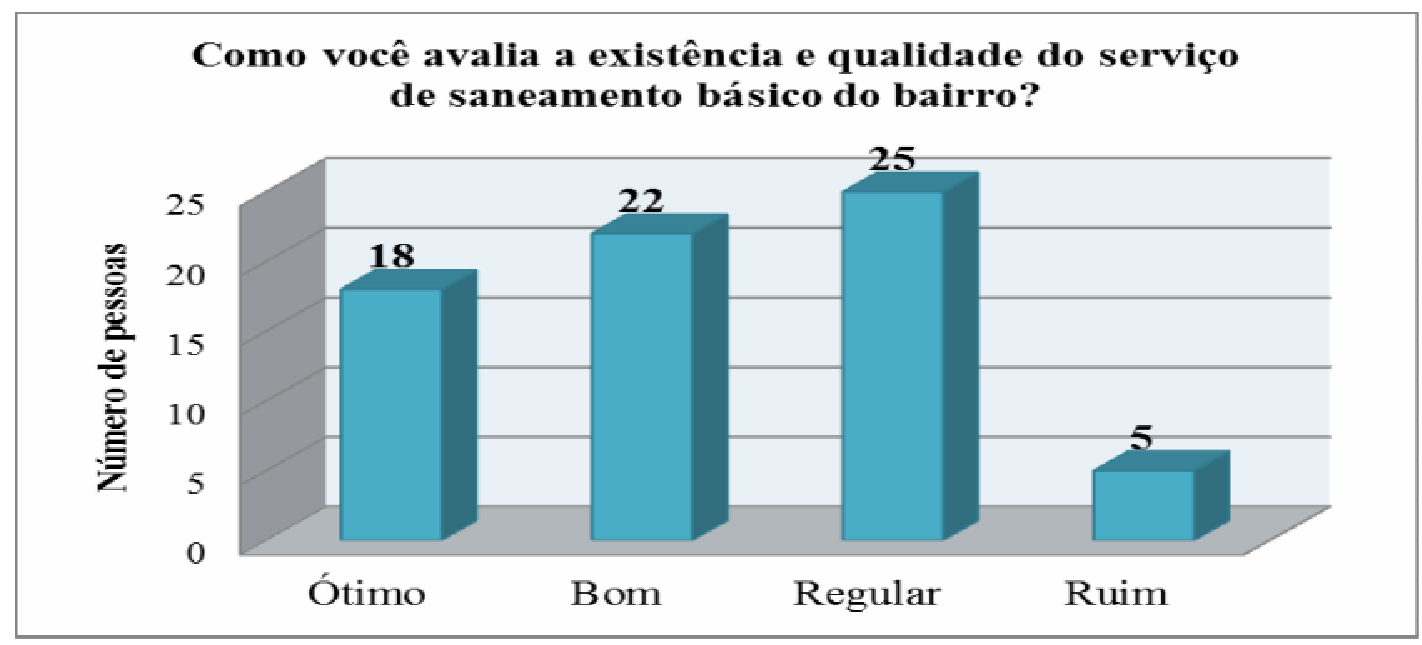

FIGURA 9 - Comparação de notas atribuídas pelos moradores ao item de saneamento básico no bairro Jardim Nova Esperança em Goiânia - Goiás. Fonte: Elaborado pelos autores. 
$\mathrm{Na}$ percepção dos residentes, a questão de saneamento no bairro não foi considerada um dos piores itens. Observa-se que houve uma quantidade significativa de pessoas, em comparação com os demais itens avaliados, que atribuíram conceito bom e ótimo ao aspecto do saneamento no bairro. No entanto, a maioria (25 pessoas) ainda consideraram a oferta desse serviço no setor como regular.

Com relação aos resíduos sólidos, dados do IBGE (2010) apontam que 4.786 domicílios do tipo casa do bairro possuíam o lixo coletado por serviço de limpeza pública ou privada. O bairro ainda não possui todos os serviços de saneamento ambiental universalizados, no entanto, com relação à coleta de resíduos sólidos urbanos e ao abastecimento com água tratada, mais de $90 \%$ dos domicílios são contemplados. Do total de domicílios existentes no Jardim Nova Esperança muitos ainda carecem de infraestrutura urbana. Os dados da Tabela 2 apontam os dois aspectos mais deficientes do bairro, a saber: bocas de lobo e arborização.

TABELA 2 - Domicílios no Jardim Nova Esperança carentes de infraestrutura urbana.

\begin{tabular}{lc}
\hline Características dos domicílios & Quantidade de domicílios (nº) \\
\hline Não existe iluminação pública & 24 \\
Não existe pavimentação & 21 \\
Não existe calçada & 76 \\
Não existe meio fio/ guia & 34 \\
Sem bueiro ou boca de lobo & 1634 \\
Não existe arborização & 1620 \\
\hline
\end{tabular}

Fonte: Organizado pelos autores in IBGE (2010)

Com relação à iluminação pública, o IBGE considera se na face em trabalho ou na face confrontante do domicílio, existia pelo menos um ponto fixo (poste) de iluminação pública. Para o aspecto de pavimentação, o instituto considera se no trecho do logradouro, na face percorrida, existia pavimentação, ou seja, cobertura da via pública com asfalto, cimento, paralelepípedos, pedras etc. No bairro em análise, 24 domicílios não possuíam iluminação pública e, em 21, não existia pavimentação.

No bairro ainda existiam 76 domicílios sem calçada e 34 sem meio fio ou guia. A drenagem de águas pluviais no setor é o aspecto mais deficiente, sendo exatamente 1.634 domicílios que não possuíam bueiro/boca de lobo na face ou na face confrontante. Observa-se ainda na Tabela 2 que em muitos domicílios (1.620) não existia árvore, ao longo da calçada, passeio e/ou em canteiro que divide as pistas de um mesmo logradouro, o que ilustra os dados do IBGE. Com relação ao saneamento ambiental, a busca pela universalização é grande, porém as políticas públicas não têm conseguido efetivá-la com vistas a alcançar toda a população, especialmente a urbana e a de regiões periféricas, que contemplam cerca de $82 \%$ da população total.

\section{CONCLUSÃO}

Foi possível concluir, a partir da pesquisa, que houveram poucas melhorias na infraestrutura urbana do bairro Jardim Nova Esperança. Após 34 anos de existência, o bairro ainda está longe de possuir condições indispensáveis de uma 
organização adequada que garanta a qualidade de vida dos moradores; o Estado tem permacecido inerte aos problemas existentes no setor, desde a época da criação, as melhorias que existem no setor são vitórias das lutas constantes dos moradores em busca da infraestrutura, equipamentos públicos e regularização fundiária.

O Jardim Nova Esperança ainda carece de serviços básicos, como esgotamento sanitário. O item lazer tem carência; os moradores não possuem parques, bosques ou praças próximos as residências. No entanto, saúde, transporte público e segurança foram os itens mais críticos na opinião dos residentes. Ao comparar a real situação desses três equipamentos comunitários, existentes no bairro, com os parâmetros estabelecidos pelo Plano Diretor, observa-se que encontram-se sobrecarregados e não atendem à legislação em vigor.

A divisão da região Noroeste, na parte que passa a ser denominada Região Mendanha, está associada à existência do subcentro existente nos bairros que compõem a região, e que se tornam alvo de revitalizações ou reabilitações na lógica de mercado, resultando na gentrificação, pela qual áreas horizontais e de baixa renda são transformadas em espaços verticalizados, para atender a uma demanda social que está dentro dos interesses do mercado imobiliário.

\section{AGRADECIMENTOS}

À CAPES e à FAPEG pelo auxílio financeiro.

\section{REFERÊNCIAS}

CARVALHO FILHO, J. S. dos. Comentários ao estatuto da cidade: Lei no 10.257, de 10. 07. 2001 e medida provisória nº 2220, de 04.09.2001. Editor: Rio de Janeiro, Lumen Juris, 2011.

CHAMIÉ, P. M. B. Contexto histórico, sob o enfoque urbanístico, da formulação e legalização do Estudo de Impacto de Vizinhança. Dissertação apresentada à Faculdade de Arquitetura e Urbanismo da Universidade de São Paulo, 2010.

CHAVES, E. G. De Invasor a Posseiro: Estado - Igreja e a Luta Pela Terra Urbana. Dissertação (Mestrado). Universidade Federal da Paraíba, João Pessoa. 1985.

GOIÂNIA. Plano Diretor, Lei Complementar no 171 de 2007. Diário Oficial nำ 4.147 de 26 de junho de 2007. Figura 07 Política de Desenvolvimento Urbano, p.78, 2007.

GOIÂNIA. Rede Metropolitana de Transportes Coletivos - RMTC. Pontos de ônibus, 2015. Disponível em: <http://www.rmtcgoiania.com.br/index.php/olho-noonibus?enviar=Acessar>. Acesso Em 19 Mar de 2015.

GOIÂNIA. Secretaria Municipal de Educação - SME/ Departamento de Administração Educacional - DAE. Unidades Educacionais da Rede Municipal de Educação - Goiânia,2011a. Disponível em: 19 Mar de 2015.

GOIÂNIA. Secretaria de Turismo e Desenvolvimento Econômico de Goiânia. Museus e Centros Culturais - Goiânia, 2011b. Disponível em: <http://www.goiania.go.gov.br/shtml/seplam/anuario2012/arquivos\%20anuario/4\%20 SOCIAL/4.3.\%20Turismo\%20e\%20Cultura/4.3.2\%20Museus, \%20Centros\%20Cultur ais/4.3.2.1.\%20Museus\%20e\%20Centros\%20Culturais\%20em\%20Goi\%C3\%A2nia. pdf.> Acesso Em 19 Mar De 2015. 
GOIÁS. Secretaria da Segurança Pública. Delegacias Distritais em Goiânia, 2011. Disponível em:< http://www.policiacivil.goias.gov.br/>. Acesso Em: em 19 Mar de 2015.

INTITUTO BRASILEIRO DE GEOGRAFIA E ESTATÍSTICA, IBGE. Censo Demográfico 2000/ 2010: Característica da população. Disponível em: http://www.ibge.gov.br/english/estatistica/populacao/censo2010/caracteristicas_da_p opulacao/resultados_do_universo.pdf. Acesso em 12 de Set. 2015

IBGE. Censo Demográfico 2010a. Disponível Em: http://www.ibge.gov.br/censo2010. Acesso Em: 13 De Set. De 2015

\section{Subnormais.}

IBGE. Censo Demográfico 2010b: Aglomerados

http://www ibge gov.br/home/estatistica/populacao/censo2010/aglomerados_subnor mais/default_aglomerados_subnormais.shtm>. Acesso Em: 8 Mai. 2015.

MARICATO, E. Brasil, Cidades: Alternativas Para A Crise Urbana. Petrópolis: Vozes, 2008.

MOYSÉS, A. A Produção de Territórios Segregados na Região Noroeste de Goiânia: uma leitura sócio-política. Texto apresentado no II Encontro \& quot; Democracia, Igualdade e Qualidade de Vida. O desafio para as cidades no século XXI\&quot;, realizado em Belém no período de 7 a 9 de outubro de 2001.

SANTOS, A. R. DOS. Metodologia Científica: A Construção Do Conhecimento. 2 Ed. Rio De Janeiro: Dp\&A Editora, p. 15 de 1999.

SANTOS, R. F. DOS. Livro: Planejamento Ambiental Teoria e Prática, Editora Oficina de Textos, p. 22 de 2004.

VEIGA, J. E. Cidades Imaginárias: O Brasil é Menos Urbano do Que se Calcula" Editora Autores Associados, Campinas, São Paulo, 2002

VILLAÇA, F. Uma Contribuição Para A História do Planejamento Urbano no Brasil. IN: DÉAK C.; SCHIFFER, S. R. (ORG.). O Processo de Urbanização no Brasil. São Paulo: FUPAM/EDUSP, 1999. p. 169-244.

VILLAÇA, F. Espaço Interurbano no Brasil. São Paulo: Studio Nobel, 1998. 